\title{
Next Generation Sequencing to Determine the Cystic Fibrosis Mutation Spectrum in Palestinian Population
}

\author{
O. Essawi, ${ }^{1}$ M. Farraj, ${ }^{1}$ K. De Leeneer, ${ }^{2}$ W. Steyaert, ${ }^{2}$ K. De Pauw, ${ }^{2}$ A. De Paepe, ${ }^{2}$ \\ K. Claes, ${ }^{2}$ T. Essawi, ${ }^{1}$ and P. J. Coucke ${ }^{2}$ \\ ${ }^{1}$ Department Master Program in Clinical Laboratory Science, Birzeit University, 9700 Birzeit, State of Palestine \\ ${ }^{2}$ Center for Medical Genetics, Ghent University, 9000 Ghent, Belgium \\ Correspondence should be addressed to P. J. Coucke; paul.coucke@ugent.be
}

Received 19 November 2014; Accepted 24 December 2014

Academic Editor: Roberta Palla

Copyright (C) 2015 O. Essawi et al. This is an open access article distributed under the Creative Commons Attribution License, which permits unrestricted use, distribution, and reproduction in any medium, provided the original work is properly cited.

\begin{abstract}
An extensive molecular analysis of the CF transmembrane regulator (CFTR) gene was performed to establish the CFTR mutation spectrum and frequencies in the Palestinian population, which can be considered as an understudied population. We used a targeted Next Generation Sequencing approach to sequence the entire coding region and the adjacent sequences of the CFTR gene combined with MLPA analysis of 60 unrelated CF patients. Eighteen different CF-causing mutations, including one previously undescribed mutation p.(Gly1265Arg), were identified. The overall detection rate is up to $67 \%$, and when we consider only CF patients with sweat chloride concentrations $>70 \mathrm{mEq} / \mathrm{L}$, we even have a pickup rate of $92 \%$. Whereas p.(Phe508del) is the most frequent allele ( $35 \%$ of the positive cases), 3 other mutations c. $2988+1 \mathrm{Kbdel} 8.6 \mathrm{~Kb}, \mathrm{c} .1393-1 \mathrm{G}>\mathrm{A}$, and p.(Gly85Glu) showed frequencies higher than $5 \%$ and a total of 9 mutations account for $84 \%$ of the mutations. This limited spectrum of CF mutations is in agreement with the homozygous ethnic origin of the Palestinian population. The relative large portion of patients without a mutation is most likely due to clinical misdiagnosis. Our results will be important in the development of an adequate molecular diagnostic test for CF in Palestine.
\end{abstract}

\section{Introduction}

Cystic fibrosis (CF) is a severe life threatening genetic disease most common among Caucasians with an incidence ranging from 1 in 2500 to 1 in 3600 [1]. CF is inherited in an autosomal recessive way and the cystic fibrosis transmembrane conductance regulator gene (CFTR), located on chromosome $7 \mathrm{q} 31.2$ [2], has been identified as the responsible gene encoding a transmembrane protein that functions as a chloride channel and a regulator of other channels across the epithelial cell membrane. The defective protein impairs water movement across epithelia leading to formation of viscous mucus that obstructs the airways of the lungs and ducts of the pancreas. $\mathrm{CF}$ is characterized by progressive lung disease, pancreatic dysfunction, elevated sweat electrolytes, and male infertility [3].

So far, more than 1900 different CFTR mutations have been reported [4]. Although most mutations are rare, the three-base-pair deletion p.(Phe508del) is most common in the Caucasian population affecting about $70 \%$ of the patients whereas in the Jewish population the p. $\left(\operatorname{Trp} 1282^{*}\right)$ is the most prevalent with a frequency of $60 \%$ [5], clearly indicating that the occurrence of mutations is highly population specific. For many ethnic or geographic populations, the mutation spectrum has been determined [6-15].

Recently, CF has been diagnosed in the Middle East ranging from 1 in 2,500 to 1 in 16,000 with different mutation frequencies according to the ethnic origin of populations [16]. However, reliable information about the frequency of CF among the Palestinians is still lacking and the spectrum and nature of mutations have not been documented yet hampering molecular diagnostics. A good insight into the nature and frequency of the mutations in a specific population is a prerequisite to set up adequate and cost-effective molecular diagnostics.

The aim of this study was to determine the CF mutation spectrum among the Palestinian patient population. Samples from 60 unrelated CF patients residing in the West Bank 
and Gaza were collected and their respective CF mutations were determined. Consequently, the mutation spectrum was compared with other ethnic groups residing in the Arabic population.

\section{Materials and Methods}

2.1. Patients and Sample Collection. A total of 60 unrelated Palestinian CF patients, 19 of them residing in the West Bank and 41 residing in Gaza, participated in this study of which 34 are males and 26 are females. Most of the participants (97\%) were children less than 18 years old. The criteria for inclusion in this study were based on the clinical diagnosis. Typical pulmonary and/or gastrointestinal tract manifestations and/or elevated sweat chloride values $(>60 \mathrm{mEq} / \mathrm{L}$, Table 1$)$ were the main criteria. Whole blood $(3 \mathrm{~mL})$ was collected in EDTA vacutainer tubes (BD). Participation in this project was based on the free will of the participants. Signed consent was obtained from each participant and/or the guardian.

2.2. DNA Extraction and Polymerase Chain Reaction (PCR). Genomic DNA was extracted and purified from whole EDTA-blood by the automated extraction apparatus Autopure LS (Qiagen) using the PureGene DNA Purification Kit (Qiagen).

Amplification of the coding region and flanking introns of the CFTR gene was conducted using the 2720 thermal cycler (Applied Biosystems). A total of 28 sets of primers were developed, flanking at least 25 intronic nucleotides away from each of the 27 exons of the CFTR gene. Primers are found in supplemental Table 1 (see supplemental Table 1 in Supplementary Material available online at http://dx.doi.org/10.1155/2015/458653). Amplification was performed with $2.5 \mu \mathrm{L}$ of the purified DNA $(50 \mathrm{ng} / \mu \mathrm{L})$ template in a total of $10 \mu \mathrm{L}$ reaction mixture. The complete mix constituted the following components: $5 \mu \mathrm{L}$ of $2 \mathrm{X}$ KAPA2G Robust Hot Start Ready Mix (Kapa biosystems), $1.25 \mu \mathrm{L}$ upstream primer $(0.1 \mu \mathrm{M})$, and $1.25 \mu \mathrm{L}$ downstream primer $(0.1 \mu \mathrm{M})$. The following amplification conditions were used: $95^{\circ} \mathrm{C}$ for $3 \mathrm{~min}$ and then $95^{\circ} \mathrm{C}$ for $15 \mathrm{sec}, 60^{\circ} \mathrm{C}$ for $10 \mathrm{sec}$, and $72^{\circ} \mathrm{C}$ for $15 \mathrm{sec}$, for $32 \mathrm{cycles}$, with final extension at $72^{\circ} \mathrm{C}$ for $1 \mathrm{~min}$. The LabChip GX (PerkinElmer, USA) capillary electrophoresis was used to assess PCR product.

2.3. NGS Sequencing. For each patient, all PCR products were pooled equimolary before they entered the Nextera sample preparation protocol (Nextera XT DNA Sample Prep Kit (Illumina, Inc., San Diego, CA)), followed by 250 bp singleend sequencing on a MiSeq instrument (Illumina, Inc., San Diego, CA). All 60 samples were labeled using 60 different index tags (Nextera, Epicentre Biotechnologies).

2.4. Data Analysis. Reads were aligned to the human genome (hg19/GRC37) using the CLCBio software package (CLC Genomics Workbench 6.0.2). All exons with a coverage lower than 20 were analysed by Sanger sequencing. We first filtered all variants classified as deleterious according to the CFTR mutation database (ENST00000003084) [4]. To identify new
TABLE 1: Patients data and sweat chloride concentrations.

\begin{tabular}{|c|c|c|c|c|}
\hline$\#$ & $\begin{array}{c}\text { Age } \\
\text { (years) }\end{array}$ & Sex & Region & $\begin{array}{l}\text { Sweat chloride } \\
\text { values }(\mathrm{mEq} / \mathrm{L})\end{array}$ \\
\hline P1 & 1 & $\mathrm{M}$ & Gaza & 113 \\
\hline P2 & 3 & M & Gaza & 85 \\
\hline P3 & 8 & M & Gaza & 111 \\
\hline $\mathrm{P} 4$ & 11 & M & Gaza & 70 \\
\hline P5 & 11 & $\mathrm{~F}$ & Gaza & 60 \\
\hline P6 & 5 & $\mathrm{~F}$ & Gaza & 100 \\
\hline P7 & 8 & $\mathrm{~F}$ & Gaza & 66 \\
\hline P8 & 3 & M & Gaza & 103 \\
\hline P9 & $<1$ & M & Gaza & 81 \\
\hline $\mathrm{P} 10$ & 1 & M & Gaza & NR \\
\hline P11 & 7 & M & Gaza & QNS \\
\hline P12 & 10 & M & Gaza & 72 \\
\hline $\mathrm{P} 13$ & 8 & $\mathrm{M}$ & Gaza & 90 \\
\hline P14 & 4 & $\mathrm{M}$ & Gaza & 60 \\
\hline P15 & 6 & $\mathrm{M}$ & Gaza & NR \\
\hline P16 & 7.5 & $\mathrm{M}$ & Gaza & 90 \\
\hline P17 & 7 & $\mathrm{M}$ & Gaza & 96 \\
\hline P18 & 6 & $\mathrm{~F}$ & Gaza & 76 \\
\hline P19 & 4 & $\mathrm{~F}$ & Gaza & 114 \\
\hline P20 & 4 & $\mathrm{~F}$ & Gaza & 118 \\
\hline P21 & 1 & M & Gaza & 77 \\
\hline P22 & 1 & $\mathrm{~F}$ & Gaza & 114 \\
\hline P23 & 10 & M & Gaza & 100 \\
\hline P24 & 3 & $\mathrm{M}$ & Gaza & 126 \\
\hline P25 & 2 & M & Gaza & 129 \\
\hline P26 & 9 & $\mathrm{~F}$ & Gaza & 105 \\
\hline P27 & 18 & M & Gaza & 42 \\
\hline P28 & 11 & $\mathrm{~F}$ & Gaza & 128 \\
\hline P29 & 6 & $\mathrm{M}$ & Gaza & 135 \\
\hline P30 & 5 & $\mathrm{~F}$ & Gaza & QNS \\
\hline P31 & 13 & $\mathrm{M}$ & Gaza & 106 \\
\hline P32 & 15 & $\mathrm{M}$ & Gaza & 60 \\
\hline P33 & 3 & $\mathrm{M}$ & Gaza & 107 \\
\hline P34 & 9 & $\mathrm{M}$ & Gaza & 46 \\
\hline P35 & 17 & $\mathrm{~F}$ & Gaza & 64 \\
\hline P36 & 1.5 & $\mathrm{~F}$ & Gaza & 129 \\
\hline P37 & 7 & M & Gaza & NR \\
\hline P38 & 2 & F & Gaza & QNS \\
\hline P39 & 13 & $\mathrm{~F}$ & Gaza & 54 \\
\hline P40 & 10 & $\mathrm{M}$ & Gaza & 62 \\
\hline P41 & 4 & $\mathrm{M}$ & Gaza & 70 \\
\hline P42 & 7 & $\mathrm{M}$ & West Bank & 117 \\
\hline P43 & 18.5 & $\mathrm{M}$ & West Bank & 121 \\
\hline P44 & 5 & $\mathrm{M}$ & West Bank & 105 \\
\hline P45 & 13 & $\mathrm{M}$ & West Bank & 100 \\
\hline P46 & 12 & $\mathrm{M}$ & West Bank & NR \\
\hline P47 & 12 & $\mathrm{M}$ & West Bank & 110 \\
\hline
\end{tabular}


TABLE 1: Continued.

\begin{tabular}{lcccc}
\hline$\#$ & $\begin{array}{c}\text { Age } \\
\text { (years) }\end{array}$ & Sex & Region & $\begin{array}{c}\text { Sweat chloride } \\
\text { values (mEq/L) }\end{array}$ \\
\hline P48 & 7 & M & West Bank & 108 \\
P49 & 8 & F & West Bank & 105 \\
P50 & 7 & F & West Bank & NR \\
P51 & 15 & F & West Bank & NR \\
P52 & 2 & F & West Bank & NR \\
P53 & 10 & F & West Bank & 87 \\
P54 & 12 & F & West Bank & 104 \\
P55 & 2.5 & F & West Bank & 110 \\
P56 & 12 & F & West Bank & 112 \\
P57 & 31 & M & West Bank & 120 \\
P58 & 3 & F & West Bank & 103 \\
P59 & 15 & F & West Bank & 45 \\
P60 & 30 & M & West Bank & NR \\
\hline
\end{tabular}

NR: no result, used to indicate nonreported results.

QNS: quantity not sufficient, used to indicate insufficient sweat samples to perform the sweat test.

mutations the data were filtered against dbSNP135 (MAF > $1 \%)$. For novel variants, causality was assessed using in silico prediction software (Alamut, Interactive Biosoftware, Rouen, France).

2.5. Mutation Confirmation. Mutations were confirmed with the INNO-LiPA CFTR17 and CFTR19 kit (Fujirebio, Europe) which provides probes for the 35 most frequent CFTRrelated mutations worldwide or by Sanger sequencing. Direct sequencing of the PCR product was performed on an ABI3130XL sequencer (Applied Biosystems, Inc., Foster City, CA). For the larger deletions or insertions and for all patients with only one or no mutation, multiple ligation-dependent probe amplification (MLPA) analysis was applied (MRCHolland, SALSA MLPA KIT P091-D1 CFTR).

\section{Results}

3.1. NGS Analysis. We applied an NGS screening strategy to efficiently identify causative mutations in the 60 unrelated Palestinian patients with a clinical diagnosis of CF. Approximately, $98 \%$ of all reads on the MiSeq were successfully mapped to the reference genome. The overall mean read depth in the target area was 344x. A read depth of 10x for $92 \%$ of the bases and 20x for $90 \%$ of the bases was obtained. Patient P9 had the best coverage with all amplicons covered with at least 20x whereas patient P7 had the lowest number of amplicons (13) with a coverage higher than 20x (data not shown).

3.2. Identification of Causative Mutations. We identified 17 different mutations in 40 patients which have previously been described as CF-causing mutations, including 3 splice sites, 5 missense mutations, 4 frame shift mutations, 3 stopcodons, and 2 exon spanning deletions (Table 2). A homozygous exon-spanning deletion was suspected when we were unable

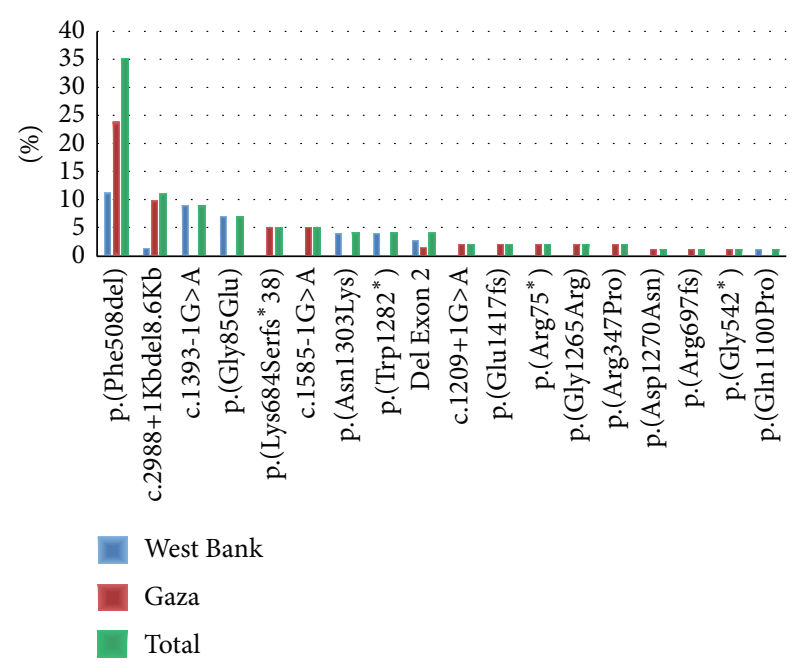

FIGURE 1: CFTR mutation spectrum among Palestinians in Gaza and West Bank.

to amplify the exons 19, 20 and 21 by PCR and consequently we did not obtain any read for these amplicons by NGS. The presence of the deletion was confirmed by MLPA analysis. In addition we identified one novel potentially deleterious homozygous missense mutation p.(Gly1265Arg) (phyloP: 5.53, Grantham dist.: 125, Sift: Deleterious, Mutation Taster: disease causing). The NGS approach does not allow, at least with the PCR-enrichment approach applied in this strategy, detection of large heterozygous deletions or insertions. Therefore, we further investigated the remaining 19 negative patients and the 3 heterozygous patients for the presence of deletions/insertions using MLPA analysis. This revealed two heterozygous deletions in patients P24 and P49. In total, we were able to detect 81 CFTR mutations on a total of 120 alleles from $60 \mathrm{CF}$ patients. Mutations were compared between $\mathrm{CF}$ patients originating from the West Bank and those from Gaza, as both regions are physically divided over 66 years. Data are represented in Figure 1.

\section{Discussion}

This is the first study to investigate the CFTR mutation spectrum in the Palestinian population that was conducted on 60 unrelated CF patients residing in the West Bank and Gaza, Palestine. We identified in 41 of these probands 81 CFTR mutations of which 18 are different. All patients are homozygous or compound heterozygous, except patient 18 , in whom we identified only one single mutation. This may be explained by the fact that the technology used in this approach does not allow detection of deep intronic mutations. The five most common mutations are p.(Phe508del) followed by the deletion of exons 19-21 (c.2988+1Kbdel8.6Kb), c.1393-1G >A, p.(Gly85Glu), and p.(Lys684Serfs $\left.{ }^{*} 38\right)$, representing $67 \%$ of all mutations (Figure 1). The homozygous p.(Gly1265Arg) mutation, which we identified in an 8-year-old male from Gaza, was never reported before. Comparing our results with a study conducted in Israel by Laufer-Cahana et al. [17] 
TABLE 2: CFTR mutations among Palestinians in Gaza and West Bank.

\begin{tabular}{|c|c|c|c|c|c|c|}
\hline c-notation & p-notation & Exon/intron & $\mathrm{dbSNP} \#$ & $\begin{array}{c}\text { \# of patients } \\
\text { Gaza }\end{array}$ & $\begin{array}{c}\text { \# of patients } \\
\text { West Bank }\end{array}$ & Patient(s) \\
\hline del exon2 & & Exon 2 & & 1 & 1 & 24 (het), 43 \\
\hline c. $223 \mathrm{C}>\mathrm{T}$ & p. $\left(\operatorname{Arg} 75^{*}\right)$ & Exon 3 & 121908749 & 1 & & 13 \\
\hline c. $254 \mathrm{G}>\mathrm{A}$ & p.(Gly85Glu) & Exon 3 & 75961395 & & 4 & $\begin{array}{c}44 \text { (het), } 56,57 \text { (het), } \\
58\end{array}$ \\
\hline c. $1040 \mathrm{G}>\mathrm{C}$ & p.(Arg347Pro) & Exon 8 & 77932196 & 1 & & 33 \\
\hline c. $1209+1 \mathrm{G}>\mathrm{A}$ & & Intron 9 & 397508176 & 1 & & 2 \\
\hline c. $1393-1 G>A$ & & Intron 10 & 397508200 & & 4 & $42,47,54,55$ (het) \\
\hline c.1521_1523delCTT & p.(Phe508del) & Exon 11 & 113993960 & 11 & 5 & $\begin{array}{c}1,3,9,11,17,19,22 \\
\text { (het), 23, } 24 \text { (het), } 28 \\
\text { (het), 29, 46, 48, } 49 \\
\text { (het), 50, 52 }\end{array}$ \\
\hline c. $1585-1 \mathrm{G}>\mathrm{A}$ & & Intron 11 & 76713772 & 2 & & 26,31 \\
\hline c. $1624 \mathrm{G}>\mathrm{T}$ & p. $\left(\right.$ Gly $\left.542^{*}\right)$ & Exon 12 & 113993959 & 1 & & 28 (het) \\
\hline c.2051_2052delAAinsG & p.(Lys684Serfs*38) & Exon 14 & 121908799 & 2 & & 8,25 \\
\hline c.2089_2090insA & p.(Arg697fs) & Exon 14 & 397508341 & 1 & & 22 (het) \\
\hline c. $2988+1 \mathrm{Kbdel} 8.6 \mathrm{~Kb}$ & & Exons $19,20,21$ & & 4 & 1 & $10,20,21,36,49$ (het) \\
\hline c. $3299 \mathrm{~A}>\mathrm{C}$ & p.(Gln1100Pro) & Exon 20 & 397508535 & & 1 & 57 (het) \\
\hline c. $3793 \mathrm{G}>\mathrm{A}^{1}$ & p.(Gly1265Arg) & Exon 23 & & & 1 & 16 \\
\hline c. $3808 \mathrm{G}>\mathrm{A}$ & p.(Asp1270Asn) & Exon 23 & 11971167 & & 1 & 18 (het) \\
\hline c. $3846 \mathrm{G}>\mathrm{A}$ & p. $\left(\operatorname{Trp} 1282^{*}\right)$ & Exon 23 & 77010898 & & 2 & 55 (het), 60 \\
\hline c. $3909 \mathrm{C}>\mathrm{G}$ & p.(Asn1303Lys) & Exon 24 & 80034486 & & 2 & 44 (het), 51 \\
\hline c.4251delA & p.(Glu1417fs) & Exon 27 & 397508706 & 1 & & 6 \\
\hline
\end{tabular}

${ }^{1}$ Previously undescribed mutation.

All mutations are homozygous except those indicated by (het).

In patients P4, P5, P7, P12, P14, P15, P27, P30, P32, P34, P35, P37, P38, P39, P40, P41, P45, P53, and P59 no mutation was detected.

In P18 only one mutation was detected.

among Israeli Arab patients showed similar rates for mutations p.(Phe508del) (34\%), p.(Gly85Glu) (8\%), and p.(Lys684Serfs*38) (8\%) and the deletion of exons 19-21 deletion (c.2988+1Kbdel8.6Kb) (13\%), confirming the common origin of both populations. Interestingly, whereas the rate of the p.(Phe508del) mutation is similar to that in the neighboring Lebanese CF population and the Jewish CF populations from Balkani (Turkish and Greeks) and Ashkenazi origins $[1,15]$, the deletion of exons $19-21$ (c.2988+1Kbdel8.6Kb) was only present in Palestinian Arabs which may indicate that this mutation is a founder mutation among this population $[18$, 19]. The two mutations p.(Gly85Glu) and c.1585-1G $>$ A, which were identified in this study, were also found among the Jewish CF populations from Balkani (9.5\%) and Ashkenazi (1\%) origins, respectively [15]. On the other hand, one of the most frequent mutations in the Jewish CF population p. $\left(\operatorname{Trp} 1282^{*}\right)(31 \%)$ was found to be less frequent in this study (4\%), similar to other Arabic CF populations such as Tunisians (4.4\%) and Algerians (4.2\%) [8, 9, 15]. The rate of the p.(Asn1303Lys) mutation was about the same in Ashkenazi Jews and the Palestinian CF population tested in this study (5\%), as well as in the Iranian (4.3\%) and Tunisian $(6.6 \%)$ CF populations $[8,11,15]$. Designing an allele specific primer based CF assay for the Palestinian population, a technology that can be easily implemented in any diagnostic setting, including the 9 most frequent mutations, would result in a test that identifies $84 \%$ of the Palestinian mutations.

The differences in the rates of mutations identified in CF patients residing in the West Bank versus those in Gaza, are remarkable. For example, mutations c.1393-1G >A, p.(Gly85Glu), p.(Trp1282X), and p.(Asn1303Lys) were only present among Palestinians in the West Bank, while mutations p.(Lys684Serfs ${ }^{*} 38$ ) and c.1585-1G > A were only present among Palestinians residing in Gaza (Figure 1). Interestingly, the p.(Phe508del) mutation was primarily prevalent among patients living in Gaza (68\%) as compared to patients in the West Bank (32\%). This may be due to the heterogeneous Arab population and the political barriers that were imposed on this population for many decades limiting their freedom of movement and concentrated the population into small communities in different geographic areas.

NGS technology combined with MLPA analysis proved to be a very efficient and cost-effective way to identify CFTR mutations. It should be noticed that heterozygous exon-spanning deletions or insertions are not observed with the PCR-based enrichment strategy followed by NGS analysis and therefore the combination of the NGS approach with MLPA analysis is highly recommended. The mutations 
included in the INNO-LIPA CFTR17 and CFTR19 kit cover only $66 \%$ of the mutations and therefore have a limited diagnostic value for the Palestinian population.

The relatively low mutation detection rate of $67 \%$ of the CF patients tested in this study is most likely caused by clinical misdiagnosis depending on the sweat chloride test. Values of this test can be influenced by nutritional state, skin condition, age, and many other factors, resulting in false positive sweat chloride values as high as $15 \%$ [20, 21]. All patients, in whom CF mutations have been identified and for whom a sweat chloride test has been performed, had a sweat chloride value higher than $70 \mathrm{mEq} \backslash \mathrm{L}$. On the other hand, most patients without a mutation have sweat chloride values lower or around $60 \mathrm{mEq} \backslash \mathrm{L}$ and therefore have a less likely clinical diagnosis of cystic fibrosis. If we only consider the former group of patients, with a sweat chloride value higher than $70 \mathrm{mEq} \backslash \mathrm{L}$, the mutation detection rate rises from 67 to $92 \%$.

In conclusion, we identified the most common CF mutations and their respective frequency in the Palestinian population. Not only is this knowledge important for the families themselves but also it is a prerequisite to set up a reliable and sensitive diagnostic test for $\mathrm{CF}$ in this population. Genetic testing in this area for recessive disorders is highly recommended because of the high rates of consanguineous marriages among the Palestinians (25\%-65\%) [22], resulting in a high risk for genetic diseases including CF [23].

\section{Conflict of Interests}

The authors declare that there is no conflict of interests regarding the publication of this paper.

\section{Acknowledgments}

The authors thank the company Fujirebio for providing them with INNO Lippa Kits. The authors also thank Dr. Abdalla Hasaballa for his help to recruit the patients.

\section{References}

[1] C. Farra, R. Menassa, J. Awwad et al., "Mutational spectrum of cystic fibrosis in the Lebanese population," Journal of Cystic Fibrosis, vol. 9, no. 6, pp. 406-410, 2010.

[2] J. Zielenski, R. Rozmahel, D. Bozon et al., "Genomic DNA sequence of the cystic fibrosis transmembrane conductance regulator (CFTR) gene," Genomics, vol. 10, no. 1, pp. 214-228, 1991.

[3] E. Dequeker, F. Accurso, S. Cabeza et al., "Classification of cystic fibrosis and related disorders," Journal of Cystic Fibrosis, vol. 1, no. 1, pp. 15-18, 2002.

[4] Cystic Fibrosis Mutation Database, http://www.genet.sickkids .on.ca/app.

[5] T. Shoshani, A. Augarten, E. Gazit et al., "Association of a nonsense mutation (W1282X), the most common mutation in the Ashkenazi Jewish cystic fibrosis patients in Israel, with presentation of severe disease," The American Journal of Human Genetics, vol. 50, no. 1, pp. 222-228, 1992.

[6] M. Rawashdeh and H. Manal, "Cystic fibrosis in Arabs: a prototype from Jordan," Annals of Tropical Paediatrics, vol. 20, no. 4, pp. 283-286, 2000.
[7] M. L. Naguib, I. Schrijver, P. Gardner et al., "Cystic fibrosis detection in high-risk Egyptian children and CFTR mutation analysis," Journal of Cystic Fibrosis, vol. 6, no. 2, pp. 111-116, 2007.

[8] S. H. Fredj, T. Messaoud, C. Templin, M. des Georges, S. Fattoum, and M. Claustres, "Cystic fibrosis transmembrane conductance regulator mutation spectrum in patients with cystic fibrosis in Tunisia," Genetic Testing and Molecular Biomarkers, vol. 13, no. 5, pp. 577-581, 2009.

[9] O. Loumi, C. Ferec, B. Mercier et al., "CFTR mutations in the Algerian population," Journal of Cystic Fibrosis, vol. 7, no. 1, pp. 54-59, 2008.

[10] M. Kambouris, H. Banjar, I. Moggari, H. Nazer, M. Al-Hamed, and B. F. Meyer, "Identification of novel mutations in Arabs with cystic fibrosis and their impact on the cystic fibrosis transmembrane regulator mutation detection rate in Arab populations," European Journal of Pediatrics, vol. 159, no. 5, pp. 303-309, 2000.

[11] R. Alibakhshi, R. Kianishirazi, J.-J. Cassiman, M. Zamani, and H. Cuppens, "Analysis of the CFTR gene in Iranian cystic fibrosis patients: identification of eight novel mutations," Journal of Cystic Fibrosis, vol. 7, no. 2, pp. 102-109, 2008.

[12] M. Bonyadi, O. Omrani, M. Rafeey, and N. Bilan, "Spectrum of CFTR gene mutations in Iranian Azeri Turkish patients with cystic fibrosis," Genetic Testing and Molecular Biomarkers, vol. 15, no. 1-2, pp. 89-92, 2011.

[13] T. Onay, O. Topaloglu, J. Zielenski et al., "Analysis of the CFTR gene in Turkish cystic fibrosis patients: identification of three novel mutations (3172delAC, P1013L and M1028I)," Human Genetics, vol. 102, no. 2, pp. 224-230, 1998.

[14] S. Orgad, S. Neumann, R. Loewenthal, I. Netanelov-Shapira, and E. Gazit, "Prevalence of cystic fibrosis mutations in Israeli Jews," Genetic Testing, vol. 5, no. 1, pp. 47-52, 2001.

[15] A. Quint, I. Lerer, M. Sagi, and D. Abeliovich, "Mutation spectrum in Jewish cystic fibrosis patients in Israel: implication to carrier screening," American Journal of Medical Genetics, vol. 136, no. 3, pp. 246-248, 2005.

[16] F. Calafell, G. Cutting, J. Dodge et al., The Molecular Genetic Epidemiology of Cystic Fibrosis: Report of a Joint Meeting of WHO/ECFTN/ICF(M)A/ECFS Genoa, Italy, June 2002, Chronic Diseases and Health Promotion, Human Genetics Programme, World Health Organization, Geneva, Switzerland, 2004.

[17] A. Laufer-Cahana, I. Lerer, M. Sagi et al., "Cystic fibrosis mutations in Israeli Arab patients," Human Mutation, vol. 14, no. 6, pp. 543-543, 1999.

[18] I. Lerer, A. Laufer-Cahana, Rivlin,J. R., A. Augarten, and D. Abeliovich, "A large deletion mutation in the CFTR gene $(3120+1 \mathrm{Kbdel} 8.6 \mathrm{~Kb})$ : a founder mutation in the Palestinian Arabs," Human Mutation, vol. 13, no. 4, p. 337, 1999.

[19] D. Saleheen, P. M. Frossard, and E. Girodon, "[3120+1kbdel8.6kb]+[p.N1303K] genotype in an Emirati cystic fibrosis patient: indication of a founder mutation in Palestinian Arabs," Journal of Ayub Medical College, Abbottabad, vol. 18, no. 3, pp. 69-71, 2006.

[20] V. A. LeGrys, "Sweat testing for the diagnosis of cystic fibrosis: practical considerations," The Journal of Pediatrics, vol. 129, no. 6, pp. 892-897, 1996.

[21] V. A. LeGrys, J. R. Yankaskas, L. M. Quittell, B. C. Marshall, and P. J. Mogayzel Jr., "Diagnostic sweat testing: the Cystic Fibrosis Foundation guidelines," The Journal of Pediatrics, vol. 151, no. 1, pp. 85-89, 2007. 
[22] S. Assaf and M. Khawaja, "Consanguinity trends and correlates in the Palestinian Territories," Journal of Biosocial Science, vol. 41, no. 1, pp. 107-124, 2009.

[23] J. Zlotogora, "Autosomal recessive diseases among Palestinian Arabs," Journal of Medical Genetics, vol. 34, no. 9, pp. 765-766, 1997. 


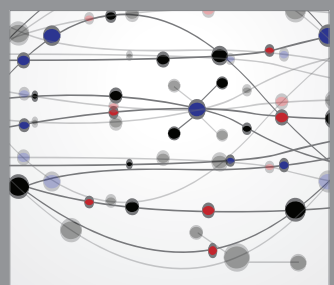

The Scientific World Journal
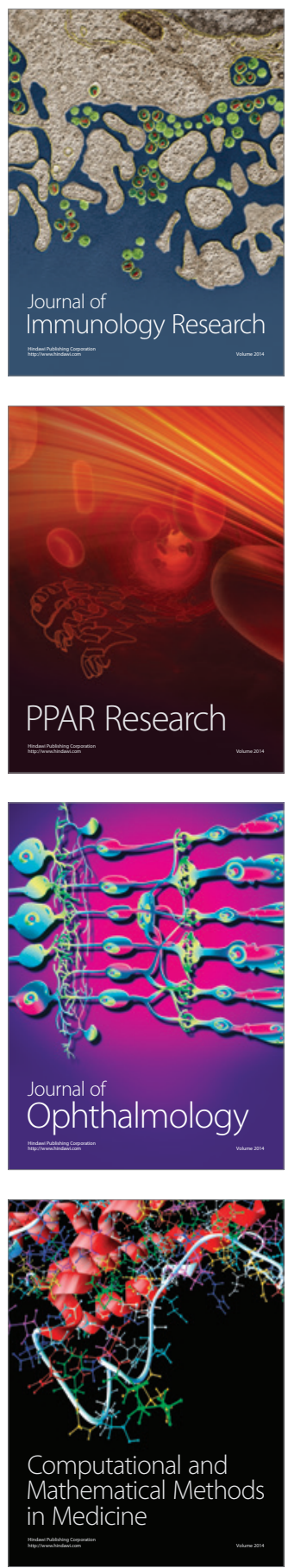

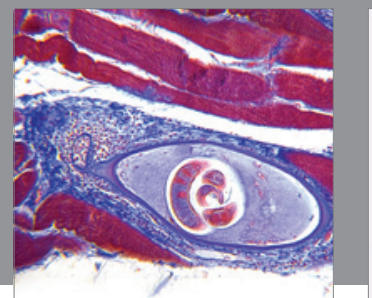

Gastroenterology

Research and Practice
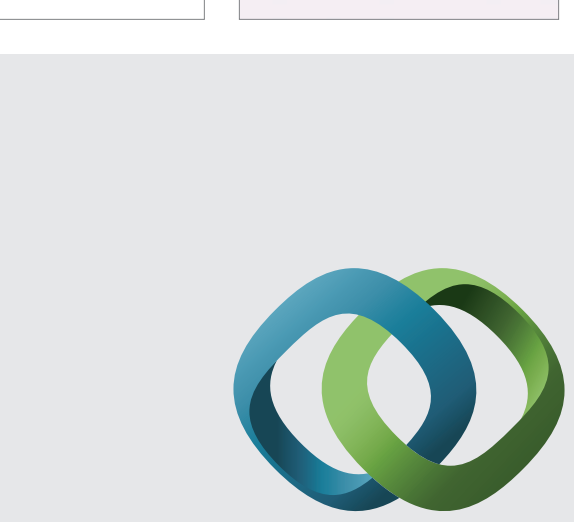

\section{Hindawi}

Submit your manuscripts at

http://www.hindawi.com
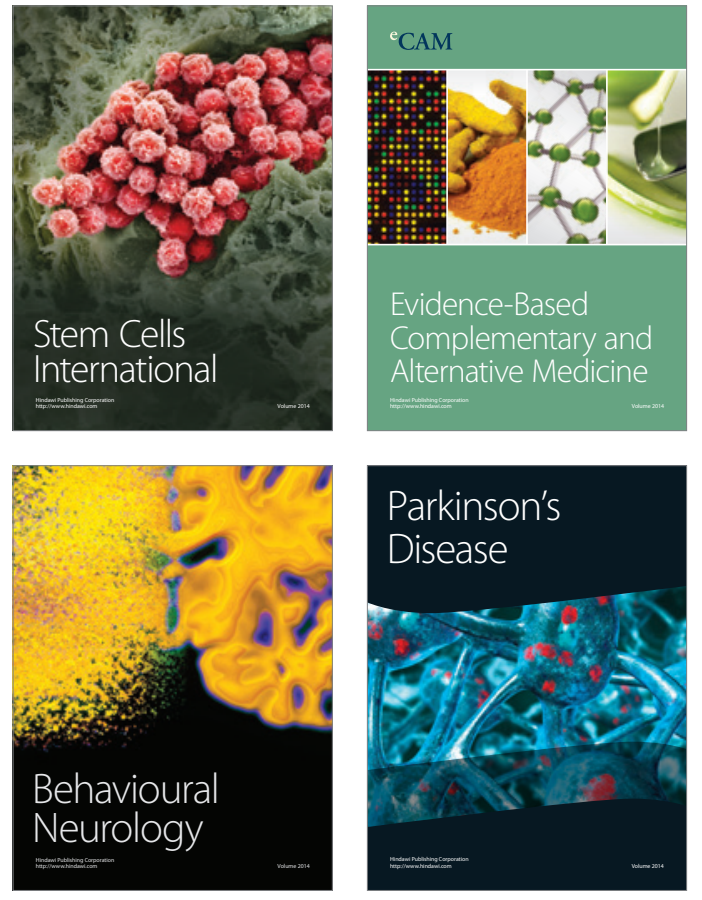
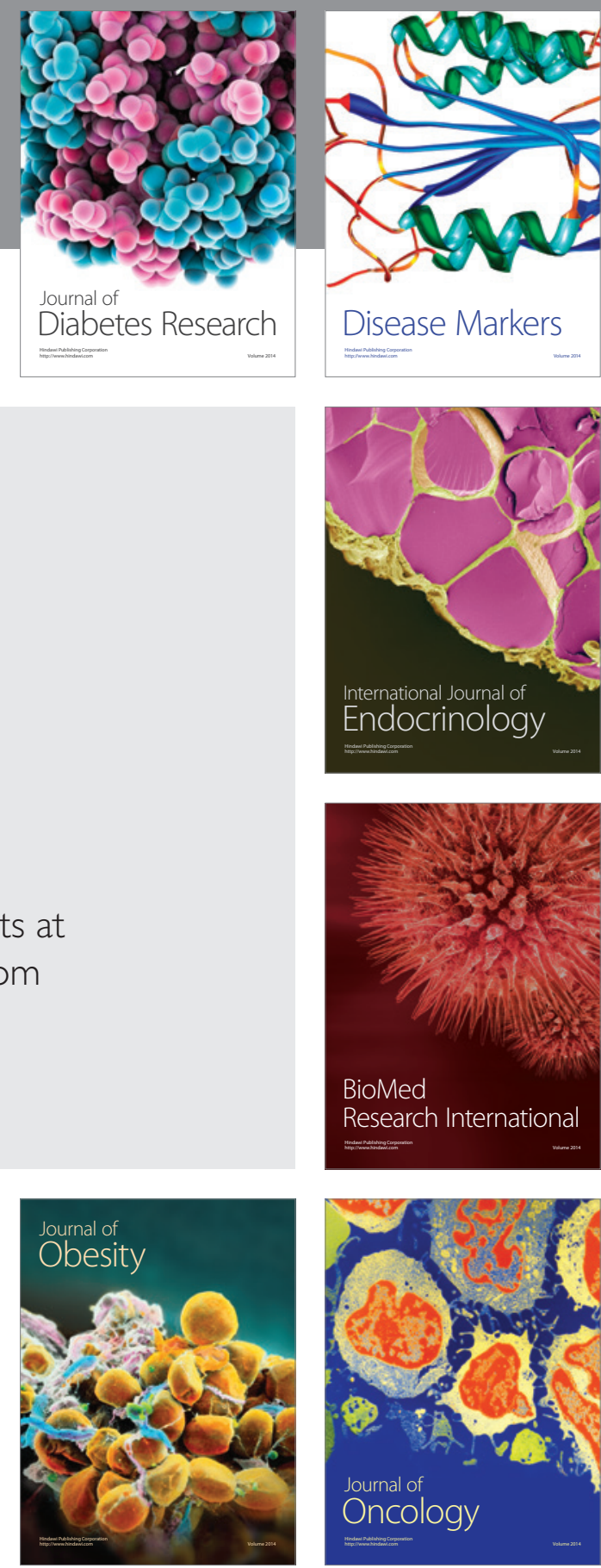

Disease Markers
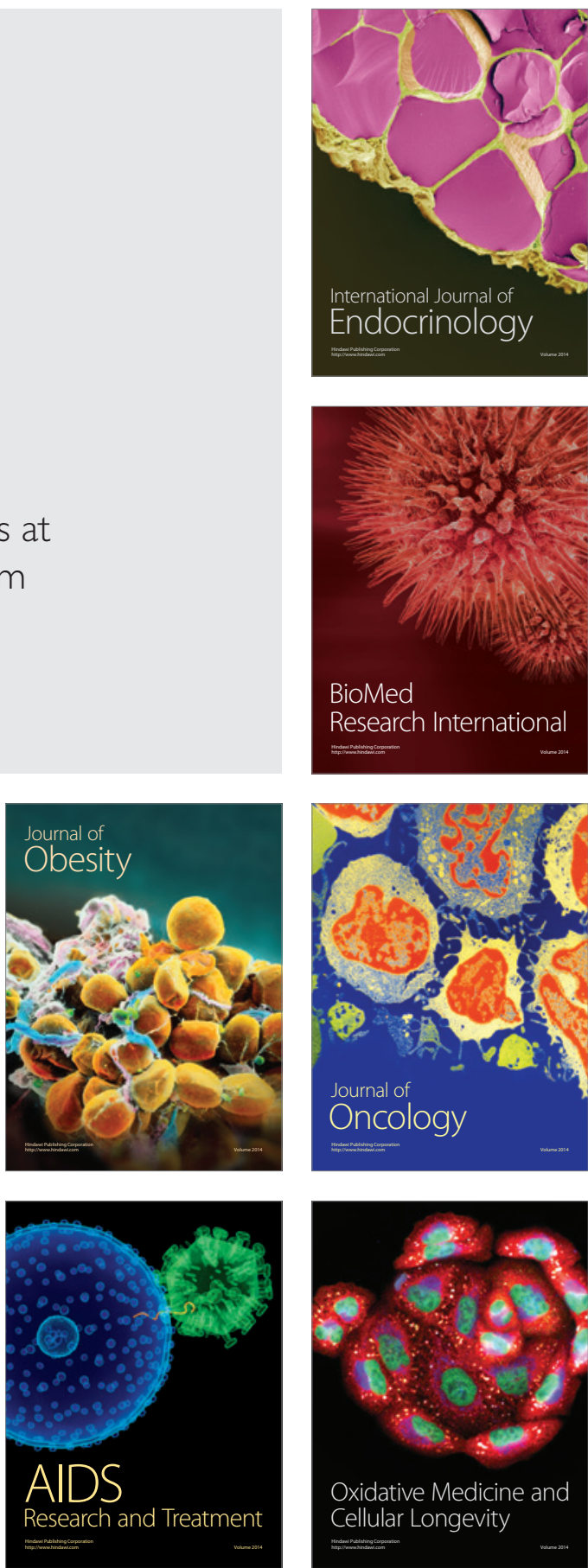